\title{
ACCURACY OF BROADRICK FLAG OCCLUSAL PLANE ANALYZER UTILIZING TWO DIFFERENT POSTERIOR SURVEY POINTS
}

\author{
Fahad H. Banasr*
}

\begin{abstract}
Occlusion and occlusal plane is the primary criterion in fabrication of posterior restorations. The Broadrick flag occlusal plane analyzer permits reconstruction of the curve of Spee in harmony with the anterior and condylar guidances. The aim of this study was to determine the accuracy of the Broadrick flag analyzer by using two different posterior survey points.

Materials and methods: Twelve subjects were selected according to certain criteria. Diagnostic casts were mounted in semi-adjustable articulator. The Broadrick flag occlusal plane analyzer was mounted on the upper member of articulator. The anterior survey point was scribed for the control mandibular dentulous side and for group 1 and 2 in the partially edentulous mandibular side while the posterior survey point was selected either from the distobuccal cusp of the mandibular second molar for the control side and group 1 partially edentulous side or the most anterior point of the condylar element of the Hanau H2 semiadjustable articular for both the control dentulous side and group 2 partially edentulous bounded side. The point of intersection between the anterior and posterior survey points is the occlusal center. The deviation of the survey center scribed on the buccal surface of the mandibular bicuspid and second molar was measured and subjected to statistical analysis.
\end{abstract}

Results: Paired samples t test or repeated measures test was used to evaluate the statistical significance between groups. The results showed that there was no statistical difference between the two reference points in the partially edentulous side but a statistical variation was found between the partially edentulous side and the control dentulous side among the leveling of the curve of Spee.

Conclusion: Broadrick flag occlusal plane analyzer is an easy precise and accurate instrument for occlusal plane analysis whether using the distobuccal cusp of the mandibular second molar or the most anterior point of the condylar element of the semi-adjustable articulator as a posterior survey points.

* Associate Professor, Oral and Maxillofacial Prosthodontics Department, Faculty of Dentistry, King Abdulaziz University, Jeddah, Saudi Arabia 


\section{INTRODUCTION}

One of the most important decisions that a restorative dentistry has to make is the determination of a functional and esthetic occlusal plane. When the patient has missing teeth or malaligned posterior teeth, that need to be replaced, it is important that these teeth are positioned in the most ideal place for the patient. The curvature of the arch in three dimensions, including the antero-posterior curve (curve of Spee) and the lateral curve (Wilson curve) as well as the placement of teeth, must be determined for treatment to be successful. ${ }^{1}$

The natural arrangement of the posterior occlusal scheme may be disturbed by rotation, tipping and overeruption of posterior teeth, most commonly following posterior tooth $\operatorname{loss}^{2}$. The challenge to the restorative dentistry when restoring posterior dentitions to design an occlusal scheme in harmony with the patient's incisal and condylar guidance, and permitting total posterior disclusion on mandibular protrusion $^{2,3}$. Such interferences have been shown to cause abnormal activity in mandibular elevator muscles, especially, the masseter and temporalis muscles ${ }^{1}$. An occlusal plane analyzer has long been used to assist the operator in the development of an initial mandibular occlusal plane in diagnostic contour casts and later as an integral part of both the contours of the definitive restorations as guides for the actual tooth preparation ${ }^{4,5,6}$. There are various types of occlusal plane analyzer which are used to determine and to establish the acceptable plane of occlusion. These occlusal plane analyzers are Wynne 2000 occlusal plane analyzer, simplified occlusal plane analyzer from Denar products and Kios analyzer ${ }^{7,8}$.

In 1963, Dr. Lawson Broadrick developed an instrument, which can be used in conjunction with various types of articulators ${ }^{9}$, to provide a guide to the most suitable position and orientation of the posterior occlusal scheme were the natural curve of Spee has been deranged ${ }^{2}$. This instrument includes a laminated piece of plastic pad snapped onto one side and attached to the superior aspect of the upper member of a semi-adjustable articulator. Its purpose is to permit reconstruction of the curve of Spee in harmony with the anterior and condylar guidances ${ }^{3}$. It requires that articulated casts of the patient's dentition be mounted in the articulator following face-bow transfer. As the curve of Spee is an arc of circle that passes through the cusp tip of the mandibular teeth and condyle, it is possible to locate the center of the curve on the Broadrick flag using a compass. Numerous studies have been conducted to assess the occlusal curvature by using the anterior and posterior survey points on the mandibular natural teeth ${ }^{9-12}$. The mandibular canine was selected as the "anterior survey point (ASP)" from which and arc of 4-inch was drawn using the compass on the Broadrick flag. The distal incline of the distobuccal cusp of the most distal molar abutment was selected as the "posterior survey point (PSP)" from which a corresponding arc of 4 inch was drawn onto the plastic card, should the position of the distal molar abutment be unsuitable then the most anterior point of the condylar element on the articulator may be selected as originally described by Broadrick ${ }^{2}$. The point of the compass should be placed at the intersection of arcs on the flag. A curve can then be drawn through the lower teeth to demonstrate the ideal position of the mandibular cusp tips.

Teeth (or portions of teeth) that are over erupted, infra-occluded, rotated or tipped can be identified and modified when restoring the posterior dentition.

The aim of this study was to detect the accuracy of the Broadrick flag occlusal plane analyzer for determination of curve of Spee by using two different posterior survey points (PSP), either the distobuccal cusps of the most distal molar abutment or the most anterior point of the condylar element of the semi-adjustable articular. 


\section{MATERIAL AND METHODS:}

A total of twelve subjects were examined and study models of their maxillary and mandibular dentition were made. The subjects were selected according to the following criteria: class I skeletal relationships, maxillary dentulous arch and mandibular class III Kennedy's classification, the missing teeth were second bicuspid and first molar, and no prosthetic restorations were involved for the edentulous part (group 1 and 2), while the other side of the mandibular arch the teeth were intact without restoration (control group). Diagnostic casts were mounted in a semi adjustable articulator (Hanau H2), the maxillary casts were mounted using arbitrary earbow while the mandibular casts were mounted using centric relation records. After mounting the casts, the maxillary cast were removed and set aside. The Broadrick flag analyzer (Whip Mix Corporation, PN 3390-6, 2012, USA) was secured to the upper of the articulator and the plastic pad snapped onto one side (Fig 1). Adjust bow compass to 4 inch radius and anterior survey point (ASP) was selected according to the technique described by Lynch and McConnell ${ }^{12}$ for both the mandibular partially edentulous (group 1 and 2) and the intact (control) sides (fig 2). The different posterior survey points were selected, either using the distobuccal cusp of the most mandibular distal abutment (group 1) or the most anterior point of the condylar element of Hanau $\mathrm{H} 2$ articulator for group 2 (fig. 3). For the control group side, both the different

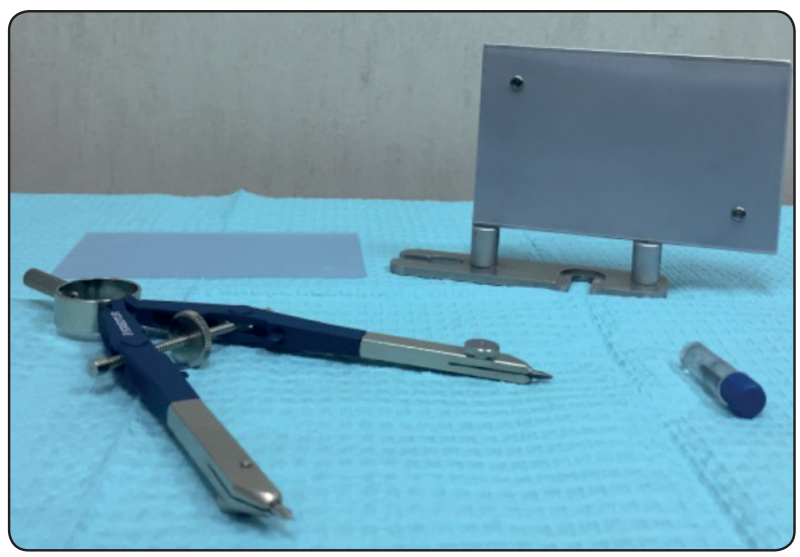

Fig (1): Broadrick flag occlusal plane analyzer.
PSP were scribed. The deviation of the survey center was measured through the different occlusal planes scribed on the first bicuspid and second molars in three areas (midbuccal, mesiobuccal and distobuccal) on both sides of the mandibular arch with the standard metal caliper (Fig 4). The data were collected, tabulated and statistically analyzed using the SPSS software (SPSS Inc. Chicago, IL,

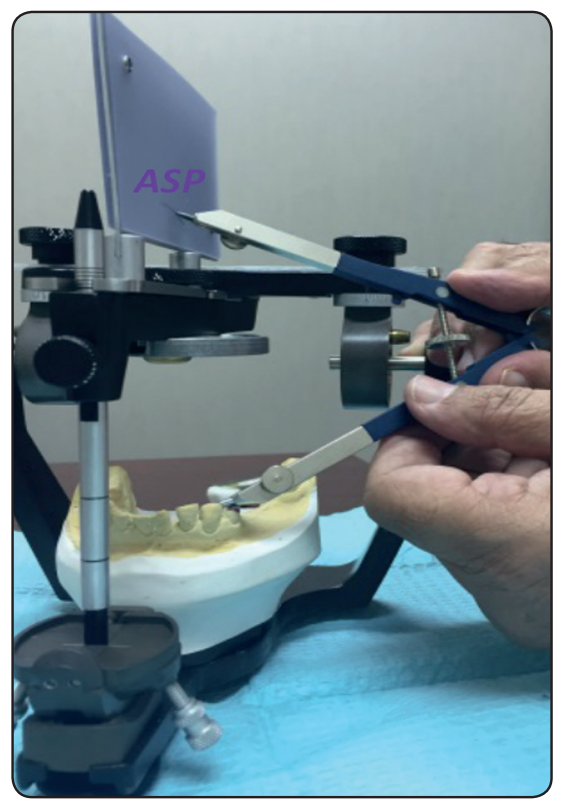

Fig (2): Determination of the anterior survey point (ASP).

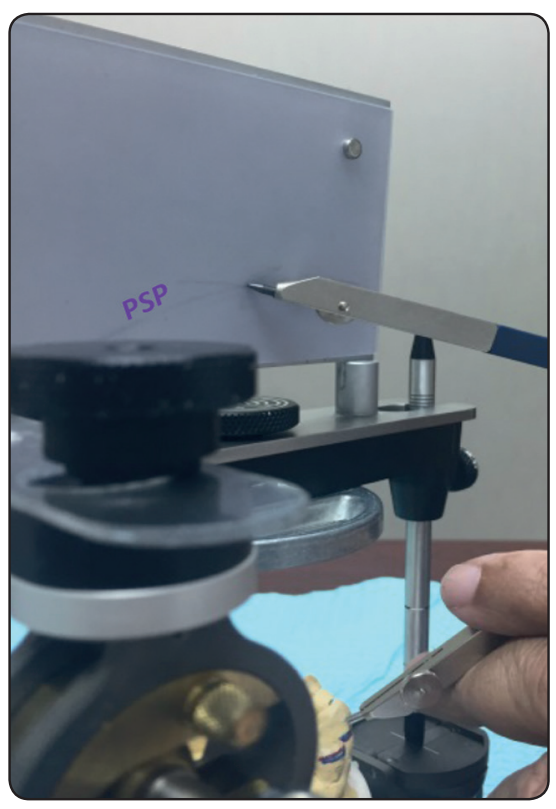

Fig. (3): Determination of the posterior survey point and point of intersection. 


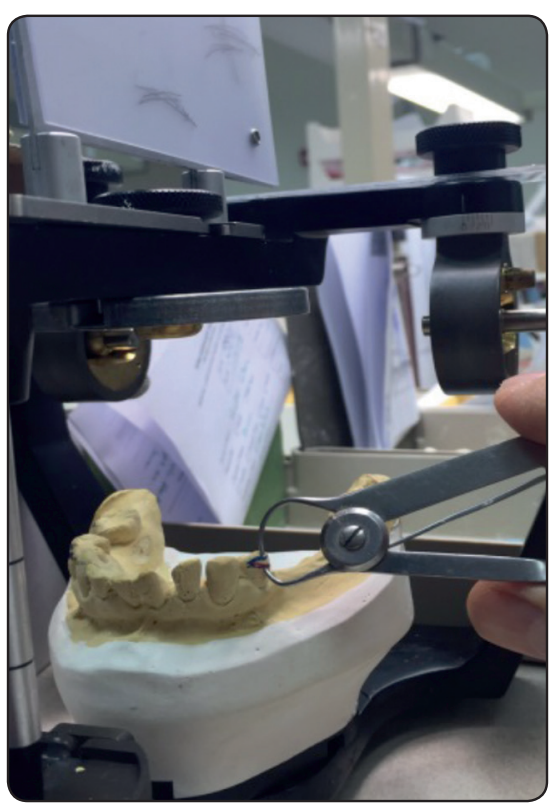

Fig. (4): Different occlusal plane lines scribed on the partially mandibular edentulous side.

USA).

\section{RESULTS:}

Paired samples $t$ test or repeated measures test was used to evaluate the statistical significance between groups. The most important advantage of this technique is the less chance that any confounding variable will influence the result and so provides greater power to detect the treatment effect.

The mean measured of PSP was $0.9 \pm 6432$ at the control side. The mean extrusion of teeth measured at the first bicuspid and second molar abutments for group 1 (disto-buccal cusp of the most distal molar abutment) was $2.1 \pm 1540$. This mean was statistically significant than that the previously measured at the control side $(\mathrm{P}=0.000, \mathrm{P}<0.5)$ (Table 1). The mean extrusion measured by the most anterior point of the articulator was $2.4 \pm 2341$. Although this mean extrusion recorded at group 2 was not statistically significant $(\mathrm{P}=0.321, \mathrm{P}>0.5)$ (Table 1) than the mean recorded extrusion of group 1. However, the paired $t$ test failed to find any statistically significant between the mean extrusion recorded in both groups (group 1 and 2) $(\mathrm{P}=0.321, \mathrm{P}>0.5)$ (Table 1).

\section{DISCUSSION}

The Broadrick flag occlusal plane analyzer was designed as an instrument to provide a guide to the location of the centre of the curve of Spee, from which a curve could be created to facilitate the restoration of a posterior quadrant ${ }^{12}$. Craddock et $\mathrm{al}^{13}$ found that the occlusal curve produced by the Broadrick flag method closely approximated the natural occlusal curve. The aims of restorative treatment for those patients with deviation of natural occlusal curve, caused by overeruption ${ }^{2}$, or tipping of teeth adjacent to site of tooth loss ${ }^{14,15}$, include the restoration of occlusal and dental form, function and the maintenance and restoration of aesthetics. The existence of a scientifically evaluated tool,

TABLE (1) Paired t samples test comparing means of overeruption

\begin{tabular}{|c|c|c|c|c|c|c|c|c|}
\hline \multirow{3}{*}{ Paired samples } & \multicolumn{5}{|c|}{ Paired differences } & \multirow{3}{*}{$\mathrm{T}$} & \multirow{3}{*}{ df } & \multirow{3}{*}{ Sig. (2-tailed) } \\
\hline & \multirow{2}{*}{$\begin{array}{c}\text { Mean } \\
\text { difference }\end{array}$} & \multirow{2}{*}{$\begin{array}{c}\text { Std } \\
\text { Deviation }\end{array}$} & \multirow{2}{*}{$\begin{array}{l}\text { Std. Error } \\
\text { Mean }\end{array}$} & \multicolumn{2}{|c|}{$\begin{array}{c}95 \% \text { Confidence Interval of } \\
\text { the Difference }\end{array}$} & & & \\
\hline & & & & Lower & Upper & & & \\
\hline $\begin{array}{c}\text { Control or } \\
\text { baseline/ group } 1\end{array}$ & 17.6532 & 4.8751 & 1.90641 & 14.3401 & 22.87642 & 9.551 & 6 & $.000^{*}$ \\
\hline $\begin{array}{c}\text { Control or } \\
\text { baseline/ group } 2\end{array}$ & 12.6541 & 4.9952 & 1.24654 & 10.65421 & 16.65321 & 9.241 & 6 & $.000^{*}$ \\
\hline Group1 / Group 2 & 18.8781 & 3.7655 & 1.38654 & 13.8766 & 23.02316 & 9.091 & 6 & 0.321 \\
\hline
\end{tabular}

$* P<0.05$, std: standard, df: degree of freedom, sig: significant 
which restores the occlusal form for an individual, allows restorative team to make an evidence base decisions when designing and restoring occlusal schemes ${ }^{16}$. The amount of occlusal plane reduction in an irregular occlusal plane affects the treatment plan procedure during construction of a removable partial denture through enameloplasty, dentinoplasty and crown or endodontic treatment and crown fixation if extruded tooth is more that certain level ${ }^{17}$. The relevance of recording and maintaining the curve of Spee is to minimize posterior protrusive interferences, which in turn prevents abnormal activity of mandibular elevators like temporalis and masseters ${ }^{10,18}$. Excursive interferences may result in wear, fracture of restorations, and temporomandibular joint dysfunction ${ }^{12}$.

Monson proposed that the mandibular teeth should be arranged to close around a sphere of 4 inch radius, with the mandibular incisal edges and cusp tips touching the sphere, thus permitting protrusive and lateral excursions free from posterior interferences ${ }^{12}$.

Lynch and $\mathrm{McConnell}^{2}$ selected the mandibular canine as the anterior survey point from which an arc of 4 ins was drawn using the compass on the Broadrick flag and the disto-buccal cusp of the most distal molar as the posterior survey point from which a corresponding arc of 4 ins was drawn onto the laminated plastic card.

Manvi et $\mathrm{al}^{1,12}$ described that 3.75 inch radius would be more appropriate when a class II skeletal relationship exists, and five-inch radius would be more suitable in a class III skeletal relationship, selection of a skeletal class I with a 4 inch was the main criteria in this study.

Few studies were reported about the accuracy of the Broadrick flag. However, most of these studies were focusing on the distal molar abutment as a posterior survey point, Craddock et $\mathrm{al}^{2,12}$ stated that should the position of the distal molar be unsuitable then the most anterior point of condylar element on the articulator may be selected. In the present study, the accuracy of the two different posterior survey points were evaluated to detect the accuracy of the Broadrick flag as an occlusal plane analyzer. The advantage of this study, all measurements were made by the same investigator to omit any confining factors. The results of this study did not seem to favor one technique over the other as a posterior survey point, either the distal molar abutment or the most anterior point of the condylar element on the articulator, which support the postulation that Broadrick flag occlusal plane analyzer is an accurate device for determination of occlusal analysis whatever the technique used for a posterior survey point.

\section{CONCLUSION}

With the use of the Broadrick flag occlusal plane analyzer, the prosthodontist can predictably produce high-quality restorations in harmony with the anterior and condylar guidance whether using the distobuccal cusp of the mandibular distal molar abutment or the most anterior point of the condylar element on the articulator as a posterior survey points.

\section{REFERENCES}

1- Manvi S, Miglani Sh, Rajeswari CL, Srivatsa G, Arora S. Occlusal plane determination using custom made Broadrick occlusal plane analyzer: A case control study. ISRN dentistry; 2012, 1-4.

2- Craddock HL, Lynch CD, Franklin P, Youngson CC, Manogue M. A study of the proximity of the Broadrick ideal occlusal curve to the existing occlusal curve in dentate patients. J. of Oral Rehabil 2005; 32: 895-900.

3- Bowley JF, Stockstill JW, Attansio R. A preliminary diagnostic and treatment protocol. Dent clin. North Am 1992; 36: 551-568.

4- Lundquist DO, Luther WW. Occlusal plane determination. J. Prosthet Dent 1970; 23: 489-498. 
5- Becker CM, Kaiser DA. Evolution of occlusion and occlusal instruments. J. Prosthodont 1993; 2: 33-43.

6- Dawson PE. Functional occlusion from TMJ to smile design. Mosby EL Sevier 2007. pp 199.

7- Toothaker RW, Gaves AR. Custom adaptation of an occlusal plane analyzer to a semi-adjustable articulator. J. Prosthet. Dent. 1999; 81: 240-242.

8- Chaffee NR, Cooper LF. Fixed partial dentures combining both resin bonded and conventional retainers: A clinical report. J. Prosthet. Dent. 2000; 83: 272-275.

9- Small BW. Occlusal plane analysis using Broadrick flag. Gen. Dent. 2005; 53(4): 250-252.

10- Davies SJ, Gray RMJ, Whitehead SA. Good occlusal practice in advanced restorative dentistry. British Dent. J. 2001; 191(8): 421-434.

11- SPSS/Win. Statistical package for social sciences under windows. Basic system's user guide release, 6.0 SPSS Inc., 1993.

12- Lynch CD, McConnell RJ. Prosthodontic management of the curve of Spee: Use of the Broadrick flag. J. Prosthet. Dent. 2002; 87: 593-597.

13- Craddock HL, Youngson CC. A study of the incidence of overeruption and occlusal interferences in unopposed posterior teeth. Br. Dent. J. 2004; 196: 341-348

14- Cragg KL, Shugars DA, Bader JD, Elter JR, White BA. Movement of teeth adjacent to posterior bounded edentulous spaces. J. Dent. Res. 2001; 80: 2021-2024.

15- Norton LA, Prolfitt WR. Molar uprighting as an adjunct to fixed prostheses. J. Am. Dent. Assoc. 1968; 76: 312-315.

16- Craddock HL, Youngson CC, Manogue M. Deviation from the Broadrick occlusal curve following posterior tooth loss. J. Oral Rehabil. 2006, 33: 423-429.

17- Phoenix RD, Cogna DR, DeFreest Ch. E. Stewart's clinical removable partial prosthodontics, 2008, $4^{\text {th }}$ ed. Quintessence Publishing Co., pp 195-197.

18- Spanko E, Pipko DJ. The use of posterior templates for cusp analysis of the cure of Spee and Wilson. Quintessence International 1986; 17: 557-60. 